\title{
O SERVIÇO DE INFORMAÇÃO AO CIDADÃO DA BIBLIOTECA MÁRIO DE ANDRADE ${ }^{1}$
}

\section{Luana Aparecida Neves \\ Severiano \\ Mestre em Biblioteconomia pela Universidade Federal do Estado do Rio de Janeiro. Bibliotecária da Prefeitura de São Bernardo do Campo. E-mail: luanaseveriano@gmail.com}

\section{Elisa Campos Machado}

Docente do Programa de Pósgraduação em Biblioteconomia da Universidade Federal do Estado do Rio de Janeiro.

E-mail: emachado2005@gmail.com

\section{RESUMO}

Apresenta uma pesquisa que tem por objetivo compartilhar a história do Serviço de Informação ao Cidadão (SIC) da Biblioteca Mário de Andrade (BMA) de São Paulo, registrando o pioneirismo da instituição e o esforço de sua equipe em oferecer ao cidadão formação para o uso e apropriação da informação, aproximando o munícipe do serviço público. Trata-se de uma pesquisa documental que adota procedimentos metodológicos da análise de conteúdo e apresenta como resultado dados referentes aos canais de informação, as fontes utilizadas à época, o quantitativo de atendimento durante o período estudado, assim como as dificuldades enfrentadas pela instituição para criar e manter tal serviço. Registra o percurso histórico do SIC com o objetivo de valorizar e difundir uma ação que foi referência na cidade de São Paulo e que serviu de inspiração para outras bibliotecas no país.

Palavras-Chaves: Biblioteca Pública; Serviço de Informação; Serviço de Referência.

\section{INFORMATION SERVICE OF MARIO DE ANDRADE LIBRARY}

\footnotetext{
${ }^{1}$ Extrato da Dissertação de mestrado apresentada ao Programa de Pós-Graduação em Biblioteconomia da Universidade Federal do Estado do Rio de Janeiro (PPGB/UNIRIO).
} 
Keywords: Public Library; Information Service; Reference Service

\section{INTRODUÇÃO}

Considerando o Serviço de Informação ao Cidadão (SIC) da Biblioteca Mário de Andrade (BMA) um marco na história da Biblioteconomia do Estado de São Paulo, a presente pesquisa apresenta uma reconstrução histórica desse importante serviço, com o objetivo de analisar os recursos e métodos empregados no período de 1979 a 2005, bem como os resultados alcançados.

A narrativa apresentada sobre o SIC da BMA foi construída a partir de uma pesquisa documental com base em um conjunto de documentos formado a partir dos critérios de exaustividade, representatividade, homogeneidade e pertinência, realizada em fontes oficiais e suplementares. Assim, foram analisados relatórios, atas de reunião, manuais, guias, catálogos elaborados pela própria instituição, trabalhos apresentados em congressos, bem como aqueles registrados por intermédio da imprensa, cobrindo o período de criação do SIC (1978), até a sua extinção, quase 30 anos. Esta literatura guarda a forma de décadas passadas, registrada em papel, datilografada ou à mão, reproduzida através de fotocopia ou mimeografada, e sofreu com a ação do tempo, o que pode ser percebido nas folhas "gastas" e grafia desbotada. Muitos destes documentos não apresentam autoria ou paginação, mas, todos pertencem a um grupo de documentos armazenados sob uma mesma origem, que é a documentação da Seção de Referência e Informação da BMA.

Investigar a trajetória do trabalho desenvolvido por outros profissionais através de documentos foi uma tarefa árdua e complexa, mas foi uma opção metodológica gratificante por entendermos que a documentação produzida pela instituição tem um valor histórico inestimável, pois dá voz àqueles que participaram efetivamente do serviço.

O objeto de estudo desta pesquisa é o Serviço de Informação ao Cidadão (SIC), da Biblioteca Mário de Andrade do município de São Paulo, instituição fundada em 1925 como Biblioteca Municipal de São Paulo, sendo hoje a maior biblioteca pública da cidade e a segunda maior biblioteca pública do país, atrás, apenas, da Biblioteca Nacional, no Rio de Janeiro. 
A BMA foi inaugurada em 1926 em um prédio da Câmara Municipal de São Paulo, situada na Rua 7 de Abril, região central da cidade. Somente em 1942, ganha um prédio próprio, na Rua da Consolação, onde se encontra até hoje (BIBLIOTECA MÁRIO DE ANDRADE, 2014).

No decorrer de sua trajetória a BMA serviu de modelo para as bibliotecas públicas no país, assim como para outras instituições culturais, ao conciliar a preservação do patrimônio histórico por meio de seu acervo com os princípios de democratização da cultura e acesso à informação. Dentre suas atividades, podemos destacar o suporte dado a pesquisadores do Brasil e exterior, sua programação cultural diversificada e seus serviços de extensão, que levavam as atividades da biblioteca para fora de suas paredes, como o "Ônibus- Biblioteca” e as "Caixas-Estantes”, iniciativas que descentralizavam o ato da leitura.

Ao oferecer um Serviço de Informação à Comunidade, a BMA ganhou relevância dentro da estrutura administrativa em que estava inserida, servindo de suporte não apenas para a população, mas também para os gestores públicos. Uma biblioteca que se propõe a institucionalizar este tipo de serviço capacita o seu público para o uso da informação, contribuindo para o "empoderamento" dos indivíduos, fazendo com que estes adquiram "a capacidade de controlar, ou pelo menos, influenciar de modo significativo, as forças pessoais, políticas, econômicas e sociais pelas quais sua trajetória existencial seria, de outra maneira, fustigada" (BAUMAN, 2007, p.162).

O uso da Tecnologia de Informação e Comunicação (TIC) no cotidiano e, principalmente, no ambiente de trabalho, tem facilitado e ampliado o acesso à informação. Todavia, em um cenário em que, segundo a pesquisa Retratos da Leitura no Brasil (2016), em 2015, apenas 55 \% da população recorda-se da existência de uma biblioteca pública em seu município, sendo que $66 \%$ deste universo não frequentam estes espaços, este artigo procura recuperar informações sobre as atividades que compunham o SIC, visando estimular infinitas possibilidades no atendimento às novas demandas informacionais de um público ainda a ser conquistado.

\subsection{Do Balcão de Informações ao SIC}

No ano de 1978, a Rádio Panamericana, mais conhecida como Jovem Pan, procurou o Departamento de Bibliotecas Públicas da Secretaria Municipal de Cultura - órgão ao qual 
a BMA era subordinada à época - para solicitar apoio na disponibilização de informações referentes à utilidade pública e apoiar os jornalistas do Programa radiofônico "Show da Manhã". Tratava-se de um espaço de jornalismo popular, que mesclava notícias, entrevistas, dicas de compras, previsão do tempo e respondia questões de utilidade pública. A BMA fornecia informações para emissora e, em troca, a Rádio divulgava a programação cultural e outros serviços da Biblioteca. Não foi encontrado documento formalizando a parceria, apenas citações ao fato em outros documentos (BIBLIOTECA MÁRIO DE ANDRADE, 198?).

Um ano após o início dessa parceria, em dezembro de 1979, foi instalado no saguão principal da Biblioteca um novo serviço denominado Balcão de Informações, subordinado à Seção de Referência e Informação, "com o objetivo de colocar à disposição da comunidade um serviço de informação que atendesse as necessidades do indivíduo em sua vida profissional e no dia a dia" (VOGADO, 200?).

É importante lembrar que no final da década de 1970 as distâncias eram consideradas bem maiores do que na atualidade, em função das condições tecnológicas da época. Manter-se informado requeria tempo, dinheiro e algum conhecimento. Os sistemas de telecomunicações eram precários e atendiam a uma parcela menor da população, visto os altos preços desses serviços ${ }^{2}$.

O Balcão de Informações pretendia amenizar estas condicionantes atendendo por telefone, carta, fax e pessoalmente pessoas não só da cidade São Paulo, mas do Brasil inteiro e de outras partes do mundo, respondendo questões sobre diferentes assuntos, (NEGRÃO; SANTIAGO; PÁSCOA, 1982), tais como:

- acervo da biblioteca: pesquisa de autor/título/assunto, horários de funcionamento das seções, programação cultural;

- $\quad$ utilidade pública: telefones da administração e serviços públicos como prefeitura, subprefeituras, delegacias e hospitais;

- como obter atendimento profissional gratuito: odontológico, jurídico, psicológico, oftalmológico, etc;

endereços de instituições: associações, sindicatos, consulados, embaixadas, museus, arquivos, escolas e organizações municipais, estaduais e federais;

\footnotetext{
${ }^{2}$ A primeira iniciativa de se estabelecer a internet no Brasil ocorreu entre os anos de 1991 a 1993, quando 21 estados do país, por intermédio da Rede Nacional de Pesquisa (RNP), obtiveram conexões em velocidade ainda baixa (Takahashi, 2000, p. 133).
} 
- indicadores econômicos: índices do dólar (turismo, oficial e paralelo), inflação, salário mínimo, taxa referencial (TR), poupança, etc. Este serviço foi o único, nesta modalidade, oferecido de maneira gratuita na cidade, e era realizado a partir das informações obtidas em jornais, as quais eram recortadas, coladas em papel sulfite e organizado em pastas;

- fatos da atualidade: dia da morte de pessoas célebres, fenômenos meteorológicos, entre outros;

- suporte nas pesquisas: prestar assessoria ao Departamento de Documentação (DEDOC ${ }^{3}$ ) da Editora Abril, Centro de Documentação (CEDOC ${ }^{4}$ ) da Rede Globo e outros canais de televisão, como Record, Bandeirantes, Gazeta e Cultura.

Para caracterizar a atividade como um serviço voltado para a disseminação da informação evitava-se, ao máximo, atender pesquisas escolares ou de caráter científico ou acadêmico, a não ser em pedidos excepcionais de outras instituições como universidades, bibliotecas e secretarias. Porém, segundo os depoimentos registrados pelos funcionários da época, o leitor nunca era desassistido, sendo sempre encaminhado para alguma instituição que pudesse atendê-lo.

Assim, o Balcão de Informações nasce com o firme propósito de servir à comunidade, não só tornando possível o encontro entre o munícipe e o serviço público, mas consolidando-se, também, como um serviço público que pretendia:

- fornecer orientação aos usuários, guiando aos setores adequados dentro da biblioteca e particularmente na Seção de Referência;

- centralizar todas as informações sobre as atividades culturais do Departamento de Bibliotecas Públicas;

- evitar a locomoção das pessoas para obtenção de informações rápidas a respeito de acervo, programas artístico-culturais, saúde, bem-estar, lazer, etc., colocando o serviço à disposição de um maior número de pessoas, através dos vários meios de comunicação: carta, telefone, emissoras de rádio, etc;

- educar o usuário na arte de informar-se. Como por exemplo: indicar o telefone da CMTC que fornece informações sobre todas as linhas de ônibus municipais, ou ligar para o no 136 que indicará a farmácia de plantão mais próxima de sua residência (NEGRÃO; SANTIAGO; PÁSCOA, 1982).

\footnotetext{
${ }^{3}$ Departamento de Documentação criado em 1968 como suporte para o trabalho jornalístico da editora Abril.

${ }^{4}$ Centro de Documentação da rede Globo, com arquivos em diversos suportes para fins de memória e suporte aos programas da emissora.
} 
Cabe ressaltar que a BMA sempre prestou um serviço que ia além de responder questões sobre o seu acervo e o universo intelectual nele contido, procurando atender as diversas necessidades de seu público. Porém, antes do Balcão de Informações, estas necessidades traduzidas em questões solicitadas pelos usuários e respondidas pelos funcionários, não eram contabilizadas e, portanto, não eram consideradas como uma atividade normativa da biblioteca.

No processo de implantação do Balcão de Informações foi definido que o acervo da própria BMA, os recursos informais (listagens ou catálogos de endereços, levantamentos, cartazes) e os recursos externos (pertencentes a outras instituições) serviriam de insumo para as pesquisas realizadas no serviço (NEGRÃO; SANTIAGO; PÁSCOA,1982).

As pesquisas eram anotadas em formulário próprio, originando um sistema de registro de informações:

- Impresso 1: constituído dos campos "solicitante", "assunto", " forma de comunicação (telefone ou pessoal)" e "registro das fontes", foi elaborado para cobrir todas as etapas da pesquisa desde a negociação entre bibliotecário e usuário até o término do processo de informação. Para cada questão levantada é utilizado um impresso, mesmo que as questões sejam frutas por apenas um solicitante.

- Impresso 2: constituído pelos campos "solicitante", "assunto", " forma de comunicação (telefone ou pessoal)" e "citações", tinha por objetivo ser anexado aos relatórios mensais, contendo dados condensados do impresso 1, podendo conter até quatro registros.

Para reunir os dados e formar o seu repertório de informações, o Balcão de Informações registrava em fichas as informações mais solicitadas, como endereços, programação cultural e cursos de formação oferecidos pela prefeitura. Estas informações eram encontradas em jornais, revistas e folhetos informativos, obtidos através de doações de órgãos oficiais e de empresas particulares, compra de publicações comerciais, recortes de jornais enviados pela Hemeroteca e da cooperação dos funcionários do serviço.

Estas publicações eram analisadas e, após minuciosa seleção, indexadas. Segundo Negrão, Santiago e Páscoa (1982), o registro de dados era feito em dois tipos de instrumentos, denominados a época de fichas e diferenciados pela cor:

- fichas brancas: continham a informação propriamente dita, podendo conter nome da entidade ou pessoa, endereço e telefone. 
- ficha rosa: registravam as fontes de informação como folhetos, recortes de jornal, e os dados para a sua recuperação, com o número correspondente à pasta onde será armazenado.

Todos estes procedimentos atendiam um público cujas pesquisas solicitadas eram heterogêneas e abrangentes, tornando-se natural que houvesse o desejo de aprimorar o Balcão de Informações que se configurava, desde 1979, como um serviço de informação de grande porte. Buscava-se, assim, solucionar, o problema geográfico do acesso à informação, pois utilizava o telefone como maior canal de comunicação. À época, o Balcão de Informações cumpria o que hoje a Lei de Acesso à Informação determina, mas, ao invés da informação disponível em ambiente digital, utilizando o telefone para diminuir a distância entre o cidadão e a informação.

\section{PROCEDIMENTOS METODOLÓGICOS}

A pesquisa documental e análise de conteúdo, principalmente, de documentos administrativos e legais, foram a base para entender o processo de criação e a gestão do SIC da Mário de Andrade.

A opção por investigar o SIC da BMA ocorreu por se acreditar que, ao se investigar o passado, reconstruindo cenários, atores e situações que, com seus acertos e erros, nos trouxeram até este momento histórico, conseguiremos aprender com estas variáveis. As práticas sociais e profissionais são resultado de uma série de ações anteriormente executadas por aqueles que vieram antes de nós e, investigá-las, nos permite rever conceitos, conjunturas e paradigmas com o distanciamento necessário para enxergamos os pontos positivos e negativos de cada ação. A reconstrução da memória do SIC, a partir da análise de conteúdo dos documentos contidos no arquivo histórico da BMA, buscou priorizar o aspecto humano, sem se desviar, no entanto, das técnicas e conceitos envolvidos em sua composição.

Segundo Sá-Silva (2009, p. 13), a importância da pesquisa documental nas ciências humanas ocorre pelo fato de que os documentos são a base de qualquer pesquisa e, dependendo do objeto estudado ou dos objetivos pretendidos, pode ser o único caminho metodológico em uma investigação ou servir de suporte para outras experiências investigativas. A pesquisa documental representa a oportunidade de estabelecer 
conexões entre os acontecimentos históricos e o momento atual, permitindo analogias, deduções e conclusões, a partir da análise de conteúdo dos documentos.

Enquanto a pesquisa documental busca a informação contida em um grupo de registros, possibilitando que documentos primários sejam descobertos entre outros registros, a análise de conteúdo nos permite, segundo Bardin (1977, p. 46), buscar as mensagens contidas nestes registros, permitindo a inferência sobre uma realidade, total ou parcialmente, desconhecida.

Bardin (1977, p. 95), divide a análise de conteúdo em três ações distintas, dispostas cronologicamente: a pré-análise, a exploração do material e o tratamento dos resultados, a partir da inferência e da interpretação.

Na pré-análise, foram escolhidos os documentos pertinentes para a pesquisa, a partir do que Bardin chama de "Leitura flutuante", ou seja, as impressões e orientações que o primeiro contato com os registros nos fornece. De acordo com a abordagem pretendida, buscou-se nos documentos selecionados os seguintes conteúdos:

- estrutura administrativa da instituição: organogramas, fluxogramas, planejamentos e avaliações;

- espaço físico: layout, mobiliário e equipamentos;

- recursos humanos: número de funcionários, suas funções, cargos e atribuições, programas de capacitação;

- acervo: coleção de obras especiais e de referência e seu arranjo para consulta, atualização e cobertura de assuntos;

- processamento técnico: apurar se há tratamento especial para as obras de referência;

- recuperação da informação: fluxo da busca de informação pelos profissionais e pelo público;

- informatização: averiguar a utilização de softwares e equipamentos;

- serviços prestados: verificar se foram somente executados para o público de modo geral ou contavam com serviços especializados;

- projetos específicos: eventos sazonais, programação cultural;

- usuários: estudos das necessidades de informação, participação da comunidade nos processos;

- comunicação: formas de divulgação do serviço e de atividades;

- parcerias institucionais: relação com outras instituições e com o poder público. 
Iniciamos a pré-análise dos documentos que, a partir da já citada "leitura flutuante", foram organizados por ordem cronológica, o que possibilitou fechar o ciclo de nascimento e encerramento do SIC.

Depois de organizar os documentos cronologicamente e observá-los analiticamente, em busca dos conteúdos já citados, foram elaborados fichamentos com o objetivo de sintetizar o assunto do documento e identificá-lo através de um cabeçalho.

A análise de conteúdo destes documentos tornou possível a construção de uma narrativa, permitindo tecer os elos entre os elementos que compõem esta trama, visando o mapeamento do SIC e a reconstituição da sua história.

\section{APRESENTAÇÃO E ANÁLISE DOS DADOS}

Os dados referentes ao funcionamento e percentual de atendimento do SIC foram obtidos na pesquisa "Biblioteca Pública e Informação: análise preliminar na Biblioteca Mário de Andrade" de autoria de May Brooking Negrão, Maria da Guia Santiago e Nina Rosa Vilas Boas Páscoa, bibliotecárias da Secretaria Municipal de Cultura de São Paulo. 0 trabalho apresentado no "1ํㅡ Congresso Latino Americano de Biblioteconomia e Documentação", realizado em 1980, em Salvador (Bahia), detalha o processo de implantação do Balcão de Informações que deu origem ao SIC/BMA. Outra fonte de dados são os relatórios anuais da BMA, na Seção de Referência e Informação: as lacunas apresentadas nos gráficos correspondem aos relatórios não encontrados nos arquivos.

Os dados apontam que aproximadamente $100 \%$ das questões formuladas pelo público obtiveram resposta e, com base nestes números, os profissionais do Balcão de Informações concluíram que:

a biblioteca deixou de ser procurada principalmente em função do seu acervo, passando a ser reconhecida como fonte de informação (fatual $55,9 \%$, assunto 16,6 , totalizando $72,5 \%$ ), cumprindo sua tarefe da formar o hábito de utilização da informação através de um uso vivo e ativo de seu acervo (NEGRÃO; SANTIAGO; PÁSCOA, 1981).

Esta constatação motivou a equipe a continuar com seus estudos e aprimorando o serviço. Muitos documentos internos e externos explicitam o êxito do Balcão de Informações: 
0 trabalho desenvolvido nestes meses demonstra que o Balcão de Informações já foi aceito pela comunidade como mais uma fonte de informação a ser usada de maneira prática e simples, seja para elevar o nível profissional e cultural do usuário, resolver problemas domésticos, de documentação, ou, simplesmente, buscar a informação e assimilá-la para satisfação pessoal (NEGRÃO; SANTIAGO; PÁSCOA, 1982).

Com esta convicção, os profissionais do Serviço de Referência e Informação da BMA continuaram trabalhando na melhoria da qualidade dos serviços durante os anos seguintes, sempre visando atender às necessidades informacionais da população para resolver seus problemas cotidianos ou, simplesmente, para manter o cidadão "beminformado".

0 atendimento, de segunda a sexta-feira, das 9 às 17 horas, era realizado pelos funcionários da Seção de Referência e Informação, entre eles, bibliotecários, pesquisadores culturais, escriturários e estagiários em biblioteconomia. Para seu funcionamento, o Balcão de Informações dispunha de um mobiliário simples e poucos equipamentos: um balcão de madeira para o acervo mais utilizado como folhetos, almanaques, guias da cidade; um armário para a guarda de material menos utilizado, como pasta de folhetos, cópia de levantamentos bibliográficos, formulários de uso do balcão, etc.; dois aparelhos telefônicos, sendo um com linha direta e outro PBX e um quadro de cortiça onde são afixados os endereços mais solicitados, programação cultural da biblioteca, avisos, etc. (NEGRÃO; SANTIAGO; PÁSCOA, 1982).

Na década de 1980 o Balcão de Informações já estava consolidado, o que levou à instalação do Balcão de Informações II, que tinha por objetivo auxiliar os usuários - no saguão da biblioteca, junto aos terminais de consulta - na utilização dos recursos da BMA e outras necessidades informacionais, estando ligado ao Balcão de Informações I por intermédio de um telefone.

Embora pudesse utilizar todo acervo da biblioteca, o Balcão de Informações constituiu, ao longo dos anos, o seu acervo próprio. A recuperação da informação era realizada por meio do catálogo e acervo do próprio Balcão de Informações, além do acervo geral e catálogo de autor/título/assunto da BMA e da parceria com outros órgãos, como empresas e instituições de ensino. Para reunir os dados e formar o seu repertório de informações, toda pesquisa realizada retroalimentava o seu catálogo, com os assuntos mais procurados sendo registrados em fichas. 
Em 1989, começa a ser delineado o projeto "Sistema de Informação para o Cidadão", sob a responsabilidade de um grupo de bibliotecárias da Secretaria Municipal de Cultura, coordenadas por May Brooking Negrão e Vera Lúcia Toikarim. A partir da constatação de que uma grande parte da população não tinha acesso à informação, o grupo apontava diversos fatores que dificultavam este acesso:

- $\quad$ inabilidade quanto ao uso das informações disponíveis motivada pela falta de formação educacional e cultural;

- falta de consciência do valor da informação como recurso para melhoria das condições sociais;

- falta de tempo para buscar a informação que nem sempre está disponível em locais próximos à residência do cidadão. São agravantes deste fator a extensão da cidade e o baixo poder aquisitivo da população que impede sua locomoção para buscar informação;

- $\quad$ dispersão das informações existentes e falta de uma coordenação entre os serviços de várias áreas;

- $\quad$ impossibilidade de utilização das informações existentes face à complexidade de sua apresentação;

- $\quad$ sobrecarga de informação, principalmente a veiculada pelos meios de comunicação de massa (NEGRAO, 1989).

As profissionais envolvidas neste projeto acreditavam que tornar possível o acesso e a apreensão da informação ampliariam a possibilidade de os cidadãos participarem politicamente da vida em sociedade, saindo de uma condição marginal para uma condição cidadã, como é registrado por Negrão (1989) ao afirmar que a intenção do novo projeto era:

- ampliar e sistematizar os serviços de informação para a comunidade existentes nas bibliotecas públicas do município, de modo a atingir aquelas pessoas na comunidade local que tem acesso limitado às fontes que podem auxiliar na solução dos problemas do dia a dia;

- centralizar as informações coletadas nas bibliotecas centrais e dos bairros, através de uma base de dados que possibilite $o$ compartilhamento e o intercâmbio de todas as informações de utilidade pública e fatuais existentes no sistema de bibliotecas públicas;

- descentralizar o fornecimento de informação, facilitando o acesso imediato à mesma pelas comunidades locais através de uma rede informatizada.

- assegurar a utilização máxima dos recursos informacionais existentes nas bibliotecas públicas em outros sistemas de informação, possibilitando a consulta por carta, telefone ou pessoalmente.

- incentivar a utilização do sistema, caracterizando para a população a biblioteca como centro de informação. 
Concomitantemente, o Balcão de Informações, mesmo com os bons números de atendimento - em 1988, por exemplo, o serviço atendeu 6.876 usuários que efetuaram 8.805 pesquisas - a falta de recursos fez com que o serviço deixasse de ser divulgado, pois não havia meios de atender um número maior de solicitações do que as já existentes. Isto acarretou, de certo modo, uma elitização no atendimento, pois somente os usuários já habituados a frequentar a BMA continuaram a utilizar o serviço.

Enquanto isso, as bibliotecas de bairro e o "Centro Cultural São Paulo" também eram acessados para fornecer informações de utilidade pública, mesmo sem contar com a estrutura operacional adequada, mas contando, principalmente, segundo Negrão (1989), com o Balcão de Informações e o acervo da BMA.

Em 1990, ocorreu a instalação do primeiro equipamento de microcomputação, no Balcão de Informações, no entanto, no decorrer do ano apresentou inúmeros problemas técnicos. Enquanto isso, as bibliotecárias do serviço participaram dos cursos "DBASE III" e "SUPERCALC IV", oferecidos pela PRODAM5. Embora as funcionárias tenham sido cedidas para o treinamento, o problema de insuficiência no quadro funcional era latente, prejudicando os serviços internos, pois a prioridade era o atendimento ao público e, para isso, outras atividades eram postergadas, tal como a implementação do projeto Sistema de Informação ao Cidadão sob a responsabilidade de Negrão e Toikarim.

No ano de 1991, outro projeto similar, com a mesma denominação, "Sistema de Informações ao Cidadão", foi elaborado pela Coordenadoria de Informações, da Secretaria Municipal de Planejamento do Município de São Paulo (SMP/SP). À época foram realizadas reuniões periódicas e discussões entre a BMA e a PRODAM para a escolha de equipamentos e programas computacionais que poderiam ser utilizados nesta nova empreitada.

Embora homônimos e com o foco no acesso à informação na cidade de São Paulo, este segundo se diferenciava do projeto elaborado em 1989 pelas bibliotecárias da Secretaria Municipal de Cultura (SMC) pelo fato de prever uma rede informatizada de acesso à informação entre todos os órgãos públicos do governo municipal, entre eles, as bibliotecas públicas.

O projeto da Coordenadoria de Informações da SMP/SP tinha por objetivo disponibilizar informações de interesse público, tornando possível otimizar a interação

\footnotetext{
5 "Companhia de Processamento de Dados de São Paulo" é, atualmente, uma empresa de economia mista, intitulada como "Empresa de Tecnologia da Informação e Comunicação do Município de São Paulo".
} 
entre o cidadão e a administração pública. Este serviço seria constituído por dados e informações enviados pelas diversas secretarias, órgãos públicos e até empresas do município que alimentavam os bancos de dados e arquivos do Sistema. Uma iniciativa do governo municipal que já previa o cumprimento da Lei de Acesso à Informação, de âmbito federal, sancionada em 2011. No entanto, a partir dos registros da BMA e de pesquisa no site da Prefeitura de São Paulo, não foi possível confirmar se essa proposta foi efetivada ou se teve continuidade em outras gestões.

Em 1991 é proposta a automação do Balcão de Informações. Originalmente esta proposta estava ligada ao projeto SIC da Coordenadoria de Informação do Município e visava o aperfeiçoamento, controle e difusão das informações que eram geradas no Balcão da BMA. Apesar da BMA ter iniciado o processo de automação de seu acervo na década de 1980 com o software DOBIS/LIBIS (SALGADO, 2008), com base nos documentos analisados constatamos que somente na década de 1990 iniciaram-se as tentativas de automatizar o Balcão de Informações.

Com o andamento do projeto Sistema de Informações ao Cidadão/SMP/SP em curso e a eminência de que todas as secretarias e órgãos municipais trabalhassem em rede, houve a preocupação de que a estrutura montada atendesse as necessidades dos usuários do Balcão de Informações da BMA.

Assim, o primeiro passo para a automatização do serviço foi a criação de um arquivo em DBASE III Plus o que resultou na inserção e atualização dos dados pelos bibliotecários da seção, possibilitando a partir desse momento a emissão de relatórios impressos. Quatro funcionários foram os responsáveis por inserirem e consolidar os 4.4550 registros na nova base de dados.

Em 1992 a BMA ficou fechada, sem atendimento ao público, de janeiro a setembro, em razão de uma grande reforma em suas instalações físicas, fazendo com que a grande maioria dos funcionários fosse remanejada para outros órgãos. No entanto, mesmo com a BMA fechada, o Balcão de Informações, continuou suas atividades fornecendo:

orientação ao público via telefone, comunicação do fechamento para outras instituições, serviços de suporte à atualização das informações através da leitura e indexação de periódicos, gerenciamento do arquivo de informações no micro, atualização dos registros via telefone e criação de novos arquivos para as informações econômicas e listagens (BIBLIOTECA MÁRIO DE ANDRADE, 1992). 
Quando a BMA reabre para o público, o Balcão de Informações é transformado no Serviço de Informações ao Cidadão (SIC) como um serviço da Seção de Referência e Informação da BMA. Com a nova denominação, o seu arquivo foi revisto, atualizado e reestruturado, os registros duplicados foram excluídos e foram também criados novos arquivos auxiliares.

Além disso, foi colocada em fase de teste a estatística detalhada do serviço, visando "o desenvolvimento de políticas de atendimento e o direcionamento dos recursos informacionais internos e externos" (BIBLIOTECA MÁRIO DE ANDRADE, 1992). Este novo modo de registro estatístico deu maior visibilidade a frequência de usuários, porém, percebemos também que está mudança fez com que os dados numéricos se sobressaiam a outros aspectos do serviço.

Podemos visualizar com mais clareza, nesse novo modelo de relatório, a estatística referente ao Valor Real da Pesquisa (VRP). Embora tenha sido identificado o uso de fator em registros de dados desde a década de 1980, somente nos relatórios estatísticos da década de 1990 o mesmo passa a ser considerado.

Cabe esclarecer que o VRP consiste na medição do grau de dificuldade da pesquisa executada: conforme a quantidade de fontes consultadas, maior a complexidade da pesquisa, de uma escala que vai de 1 a 6 documentos consultados por questão atendida.

Mesmo sem divulgação e com apenas uma linha telefônica disponível (cujo número sofreu alterações ao longo do tempo), houve números significativos de consulta: foram 1.474 solicitações por telefone; 266 pesquisadores autorizados a entrar no espaço e 15 cartas direcionadas ao serviço, totalizando 1.755 atendimentos (BIBLIOTECA MÁRIO DE ANDRADE, 1993).

Durante o ano de 1993, o SIC contou com duas bibliotecárias para atender usuários por telefone, carta e pessoalmente, sendo que:

as pesquisas giraram em torno de autor/título/assunto e dependendo do momento histórico da nação (no caso, o plebiscito) e da economia do país, tiveram ênfase para os indicadores econômicos). Demos informações sobre a BMA (dependências e circulante) e muitas pesquisas sobre orientações de utilidade pública, de um modo geral. (BIBLIOTECA MÁRIO DE ANDRADE, 1993).

Neste ano, o serviço contabilizou 10.936 usuários resultando em 12.428 pesquisas, sendo que o telefone era o principal canal de comunicação, 7.133 usuários o utilizaram. 
Já o uso de correio eletrônico por sua vez só foi visualizado em 3 ocorrências. É importante lembrar que o correio eletrônico surgiu antes da internet, permitindo a comunicação escrita de modo off-line entre usuários, através de programa especializado para computadores em rede (REDE NACIONAL DE PESQUISA, 1997).

Em matéria do jornal "O Estado de S. Paulo" publicada em 05 de dezembro de 1993 de sobre a modernização das bibliotecas, o SIC mereceu destaque. Foi considerado, um dos grandes sucessos da BMA.

Em 1994 a BMA contabilizou 244.030 usuários, sendo que destes, 107.745 foram atendidos pelo Setor de Referência e Informação. Coube ao SIC atender 11.856 pessoas que recorreram à biblioteca, porém, o grande contingente de solicitações chegou por meio do telefone, 8.904. É notável que, neste período, já havia registros de quatro solicitações de informações por meio eletrônico, assim como a utilização do microcomputador para a consulta a índices econômicos e arquivos do SIC (BIBLIOTECA MÁRIO DE ANDRADE, 1994),

No ano de 1995, a BMA recebeu 233.969 usuários, e o SIC foi acionado por 10.824 pessoas, sendo que na maioria das vezes por telefone (7.380 atendimentos), gerando 14.276 pesquisas. Esses dados mostram uma leve diminuição do número de usuários que utilizaram o Serviço em relação ao ano anterior. (BIBLIOTECA MÁRIO DE ANDRADE, 1995).

As atividades desenvolvidas pelo SIC eram executadas por duas bibliotecárias, que tinham por atribuição entre outras coisas, atualizar as pastas de índices econômicos, de endereços e telefones das entidades indexadas, indexação de novos folhetos e também vários levantamentos bibliográficos solicitados por carta.

Em 1995, uma das mais relevantes iniciativas da Seção de Referência e Informação foi, certamente, a elaboração da publicação da "Análise de Obras de Referência da Biblioteca Mário de Andrade". Sob a coordenação de Vera Lúcia Pinheiro da Silva, o documento foi elaborado "como objetivo facilitar o trabalho dos bibliotecários na busca das informações para atender os usuários de uma forma mais rápida e eficaz". (BIBLIOTECA MÁRIO DE ANDRADE, 1995). A publicação se constituiu num guia sucinto, com as principais características de 100 obras divididas por classes (000 a 900) e, que em seu final, apresenta um índice geral de autores e títulos, que se configurou em mais um instrumento de trabalho para o SIC. 
Em 1996, o SIC teve, em média, de 80 a 100 pesquisas por dia, feitas de modo "meticuloso, artesanal" e com muito tato para atender solicitações do Brasil inteiro e até de outros países com apenas dois funcionários. Para facilitar este processo foi solicitado mais um microcomputador e um aparelho de fax, visando "agilizar e automatizar nossos trabalhos diários, facilitando a indexação de dados, agilizando as respostas aos leitores e qualificando ainda mais nosso trabalho que é de vital importância para o cidadão" (BIBLIOTECA MÁRIO DE ANDRADE, 1996).

Em toda a documentação é recorrente as solicitações de aquisição de computador, aparelho de fax entre outros equipamentos para qualificar o serviço e acompanhar o desenvolvimento tecnológico em processo no país e no mundo, no entanto, estas solicitações não eram atendidas e os trabalhos eram realizados com base em documentos e catálogos em suporte de papel.

No total, em 1996 foram atendidos 10.322 usuários, resultando em 15.957 pesquisas, cuja maioria solicitava informações de utilidade pública (8.290), resultando no "Valor Real de Pesquisa" (VRP) de 17.823, em um universo onde o número total de usuários que passaram pela BMA foi de 203.387 pessoas. Uma leve queda no número de usuários pode ser observada em relação ao ano anterior, mas permanecendo no patamar de mais de 10.000 pessoas atendidas anualmente (BIBLIOTECA MÁRIO DE ANDRADE, 1996).

Em 1997 é possível verificar o empenho dos profissionais da Seção de Referência e Informação em obter não somente um maior número de informações para o SIC, mas mantê-lo atualizado, realizando uma ampla cobertura de assuntos e recorrendo a organizações internas e externas à administração pública do município de São Paulo. São adquiridos itens relevantes para o acervo, sejam publicações regulares, de ampla circulação ou, publicações oficiais, como o "Livro da Cidade de São Paulo" e, até mesmo, publicações corporativas, como "Dicas de Brasília 97".

$\mathrm{Na}$ época, o acervo era atualizado graças às doações realizadas pela Editora Abril que disponibilizava algumas de suas publicações de cunho geral e referencial, tais como o "Almanaque Abril", o "Guia de Ruas" e "Guia do Estudante", consideradas "básicas e indispensáveis" para o serviço.

Com tantas dificuldades, em 1997, 11.659 usuários utilizaram o serviço, em universo de 233.879 pessoas que comparecem à BMA no mesmo período. Estes 11.659 usuários geraram 18.084 pesquisas, resultando em um VRP de 20.124. Assim, os números 
de atendimento mostram um leve acréscimo de público em relação a 1996 (BIBLIOTECA MÁRIO DE ANDRADE, 1997).

Em 1998, passados 20 anos de sua abertura, o SIC funcionou com apenas dois funcionários fixos para atender os leitores pessoalmente, carta ou telefone; atualizar as pastas de indicadores econômicos e o catálogo de entidades; indexar e revisar as pastas de folhetos. Vale dizer que durante este período a Seção de Referência e Informação tinha em seu quadro apenas 11 funcionários, sendo 5 bibliotecários, para cobrir, além do SIC, o Seção de Referencia, gerando dificuldades no atendimento que se intensificavam em caso de ausências dos servidores, tais como férias, abonos, licenças médicas, programadas ou não. Na Figura 1, nota-se como o SIC mantém uma frequência estável de usuários na década de 1990, mostrando a relevância do serviço para a população.

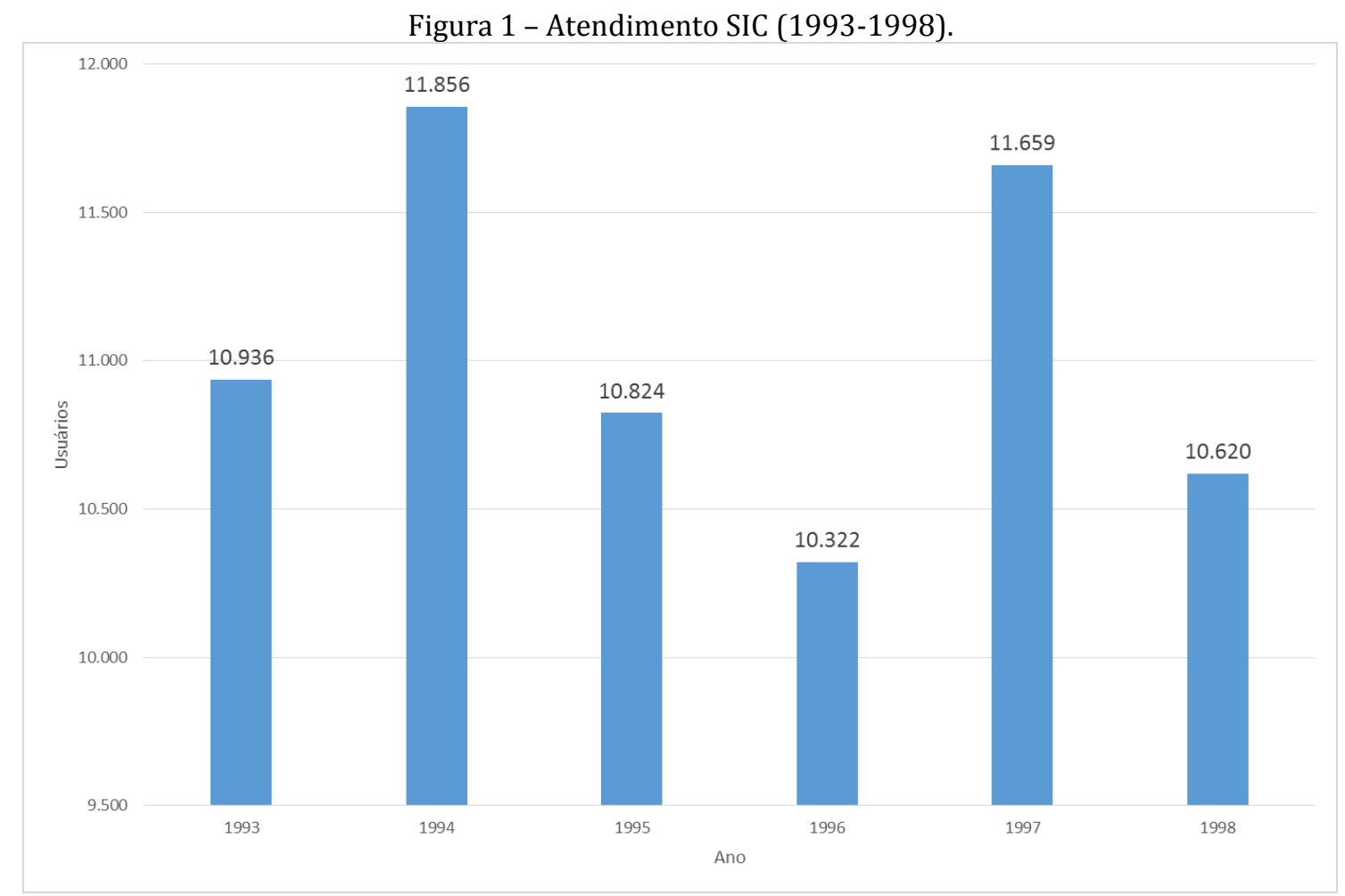

Fonte: Dados da Pesquisa.

Assim, a cada ano subsequente foi se evidenciando que as atividades executadas pelo SIC ficaram concentradas na rotina de atualização das pastas de indicadores econômicos e das informações sobre a administração pública nas três esferas. Pouca inovação foi verificada. 
Contudo, a inauguração do "Poupatempo6" e do "Serviço de Informação Jurídica ao Cidadão7" (SIJ), fez com o que o interesse pelo SIC fosse renovado, levando a visitas exploratórias para conhecer o seu funcionamento. Servindo como exemplo para este tipo de Serviço, até então, uma novidade na administração pública municipal no Brasil. Neste ano, o número de usuários do SIC - janeiro a novembro - foi de 10.620, sendo que a maioria por intermédio de telefone 7.121, originando 19.942 pesquisas, cuja soma total de VRP é 21.504 (BIBLIOTECA MÁRIO DE ANDRADE, 1998).

Cabe registrar que não foram identificados indícios de que os projetos das bibliotecárias da SMC e da Coordenadoria de Informações da SMP/SP foram implantados em sua totalidade. Novos registros sobre estas iniciativas não foram encontrados nos documentos examinados. Acreditamos que a mudança de gestão, em 1993, a quem não encontramos nenhuma menção direta em documentos analisados, não foi favorável ao desenvolvimento destes projetos e o espírito inovador de seus idealizadores não conseguiu se materializar devido à falta de recursos. Mesmo assim, o SIC permaneceu na ativa, conseguindo atravessar mais uma década.

As primeiras tentativas de implementação da internet no Brasil foram na década de 1990 e o Brasil tinha urgência para que “A sociedade da Informação” fosse estabelecida no país. Assim, acreditava-se que:

Na era da Internet, o Governo deve promover a universalização do acesso e o uso crescente dos meios eletrônicos de informação para gerar uma administração eficiente e transparente em todos os níveis. A criação e manutenção de serviços eqüitativos e universais de atendimento ao cidadão contam-se entre as iniciativas prioritárias da ação pública. Ao mesmo tempo, cabe ao sistema político promover políticas de inclusão social, para que o salto tecnológico tenha paralelo quantitativo e qualitativo nas dimensões humana ética e econômica (TAKAHASHI, 2000, p.v).

Todavia, a cidade de São Paulo encontrava-se sem condições para que tais premissas se consolidassem em seu território e os equipamentos culturais estavam abandonados.

\footnotetext{
${ }^{6}$ Implantando em 2006, é um órgão que reúne, em um único local, um amplo leque de órgãos e empresas prestadoras de serviços de natureza pública.

${ }^{7}$ Atualmente, Sistema de Informações Jurídicas (SIJUR), é uma base de dados que procura sistematizar todas as legislações federal, estadual e municipal, de interesse de regiões metropolitanas do Estado de São Paulo.
} 
Em 2002, 7.661 usuários foram atendidos pelo SIC, representando uma queda significativa em relação à década anterior. O quadro abaixo descreve os canais de atendimento no ano.

Quadro 1. SIC - Canais de atendimento - Dados de 2002

\begin{tabular}{|l|c|}
\hline \multicolumn{1}{|c|}{ Canais } & Usuários \\
\hline Atendimento - Telefone & 5.014 \\
\hline Atendimento - Pessoal & 2.627 \\
\hline Atendimento - Carta & 20 \\
\hline Correio Eletrônico & 0 \\
\hline Total & $\mathbf{7 . 6 6 1}$ \\
\hline
\end{tabular}

Fonte: Biblioteca Mário de Andrade (2002).

Dessas questões, a maioria abordava orientações sobre utilidade pública (5.886), seguida por questões referentes à BMA (2.598), o que mostra que o serviço era efetivamente para elucidar problemas cotidianos do homem comum (BIBLIOTECA MÁRIO DE ANDRADE, 2002).

Em 2003, a Seção de Referência e Informação, devido à rotineira problemática de falta de pessoal não pode atualizar o catálogo de entidades do SIC. Neste ano, em que a BMA recebeu 173.258 leitores (BIBLIOTECA MÁRIO DE ANDRADE, 2003) o SIC contabilizou os seguintes números:

Quadro 2. SIC - Canais de atendimento - dados de 2003

\begin{tabular}{|c|c|}
\hline Canais & Usuários \\
\hline Atendimento - Telefone & 4.081 \\
\hline Atendimento - Pessoal & 2.524 \\
\hline Atendimento - Carta & 03 \\
\hline Correio Eletrônico & 02 \\
\hline Total & $\mathbf{6 . 6 1 0}$ \\
\hline
\end{tabular}

Fonte: Biblioteca Mario de Andrade (2003)

$\mathrm{Na}$ maioria das pesquisas as fontes utilizadas foram o do próprio serviço, respondendo, majoritariamente, a pesquisas sobre utilidade pública: 5.026 de um universo de 12.763 questões atendidas, resultando em um VRP de 14.690.

No Relatório Anual de 2004, evidencia-se a diminuição de leitores na BMA, 162.317 contra 173.258 do ano anterior, e a persistência do problema de falta de funcionários, o que ocasionou o estancamento dos serviços internos em prol do atendimento. Em outubro deste ano, o SIC passou para uma nova sala, no andar térreo, onde ficava a sala de catálogos autor/título. 
Neste ano, o SIC é acionado por 6.780 pessoas através, principalmente, de telefone, 4.073 atendimentos, e vemos que as questões sobre a BMA que totalizaram o quantitativo de 3.960, estavam alcançando o número de questões referentes à utilidade pública, 4.792, ou seja, o SIC estava deixando de ser um serviço de informação social e se reduzindo a um suporte para a própria BMA.

A partir desses dados, creditamos que o SIC passou a ser substituído por outros serviços e fontes de informação, tais como o PoupaTempo e os periódicos eletrônicos já disponíveis na internet. Nessa época já era possível visualizar o crescimento do uso da internet no país, mas o SIC continuava sem suporte tecnológico adequado, trabalhando através de documentos em suporte físico e linha telefônica.

O ano de 2005 foi muito difícil para a Seção de Referência e Informação, havendo dificuldade no atendimento em diversos pontos da Seção:

O SIC permaneceu fechado durante quase todo o ano e só atendemos algumas pesquisas mais urgentes que chegavam por telefone e pesquisas enviadas pelo Portal da Prefeitura que chegaram por e-mail. Porém não podemos deixar de agradecer a dedicação dos funcionários da referência e o auxílio de colegas de outras seções. Com a falta de funcionários não pudemos realizar outras atividades como o inventário do acervo e atualização do catálogo de entidades do SIC. Entretanto começamos a fazer a revisão das pastas de folhetos e continuamos o trabalho de montagem das novas pastas-sumários de livros didáticos (BIBLIOTECA MÁRIO DE ANDRADE, 2005).

Neste período, o acervo do SIC era composto majoritariamente de obras doadas que não passavam pelo processamento técnico, deixando transparecer o enfraquecimento do serviço perante a própria BMA e aos olhos do público, fato corroborado pela estatística: se compararmos os números de atendimento em 2005, com os apresentados em 1985, percebemos uma significativa queda:

Quadro 3. Serviço de Informação ao Cidadão - Canais de atendimento comparação entre os anos 1985 e 2005

\begin{tabular}{|l|c|c|}
\hline \multicolumn{1}{|c|}{ Canais } & Usuários atendidos em 1985 & Usuários atendidos em 2005 \\
\hline Telefone & 10.115 & 1.651 \\
\hline Pessoal & 4.197 & 1.442 \\
\hline Carta & 117 & 0 \\
\hline Correio Eletrônico & 0 & 16 \\
\hline VRP & 0 & 5.868 \\
\hline Total & $\mathbf{1 4 . 4 2 9}$ & $\mathbf{3 . 1 0 9}$ \\
\hline
\end{tabular}

Fonte: Biblioteca Mário de Andrade (2005). 
Além da diminuição de público - apenas 3.109 solicitações - outro fato significativo é a equiparação entre o número de questões sobre a BMA (1.795) e as orientações sobre a utilidade pública (1.859), evidenciando a descaracterização do serviço como polo irradiador de informações para a vida cotidiana.

Esta redução no atendimento vinha sendo acompanhada - ou agravada - pela escassez de recursos humanos e materiais. Em relatório que analisa as condições da Seção de Referência e Informação, é possível conferir que o SIC, cujo atendimento continuava das 9 às 17 horas, estava sofrendo com a falta de infraestrutura (equipamentos, acesso à internet) e de funcionários. Na Figura 2 fica evidente a diminuição da procura pelo serviço a partir de 2002:

Figura 2- Atendimento SIC (2002-2005).

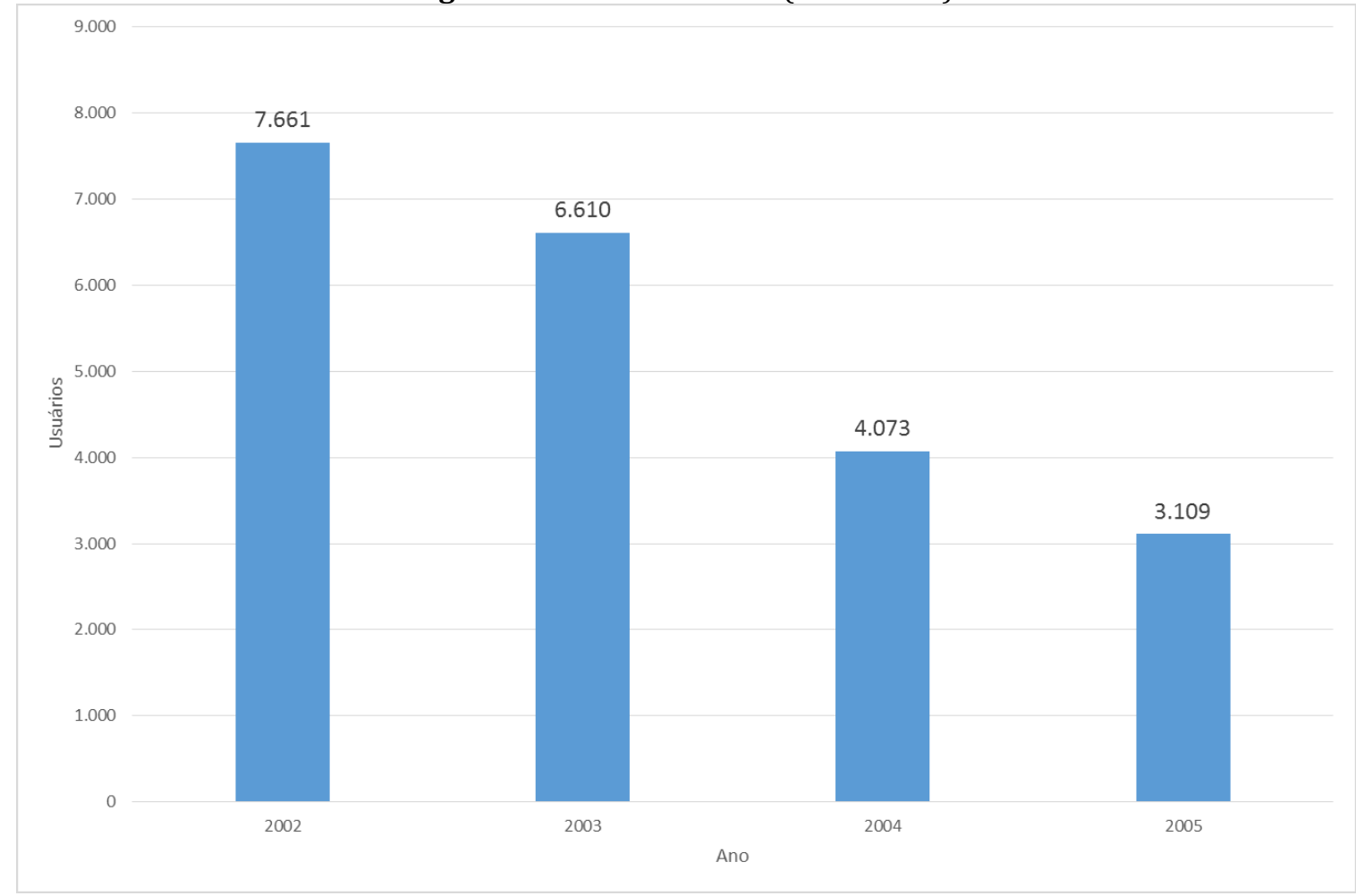

Fonte: Dados da Pesquisa.

0 encerramento do SIC nunca foi oficializado. Não encontramos em meio à documentação da BMA menção a sua extinção, no entanto, segundo Villani (2014) os acontecimentos que levaram à extinção do serviço se iniciaram em outubro de 2004 quando o SIC mudou de sala e passou a funcionar ao lado da Sala de Leitura, no andar térreo da BMA, em um espaço onde, anteriormente, eram guardados catálogos de fichas referentes ao acervo da BMA. Em novembro deste mesmo ano, foi feita a solicitação para 
a instalação de um ponto de rede para a internet para suprir as necessidades do SIC, pedido que nunca seria atendido. Em 2005, os problemas referentes à insuficiência no quadro de funcionários se intensificaram resultando no fechamento temporário do SIC.

No período entre dezembro de 2007 a outubro de 2010 a BMA passou por uma grande reforma física que incluiu intervenções na estrutura do prédio, restauro do mobiliário, a desinfestação de livros, higienização e reorganização de todo o acervo. Em 2010, antes do término da reforma, ela reabre parcialmente, com o setor "Circulante" e, em 25 de janeiro de 2011, a Biblioteca foi reinaugurada, porém, sem seu serviço de informações, já que o SIC não foi reaberto.

\section{CONSIDERAÇÕES FINAIS}

Acredita-se que as dificuldades em manter um número adequado de funcionários e a escassez de recursos tecnológicos, aliados ao avanço das novas Tecnologias de Informação e Comunicação (TIC) e as iniciativas do poder público municipal e estadual para disseminar a informação, foram as causas mais proeminentes para o fechamento do SIC da BMA.

No entanto, a importância do SIC para a promoção da informação no município de São Paulo, desde o final da década de 1970 com o Balcão de Informações, é ratificada pelos registros históricos que comprovam o pioneirismo e a qualidade do atendimento prestado, assim como os esforços para implantar e manter um sistema de informação abrangente para o cidadão.

Acredita-se que, ao oferecer um serviço de informação à comunidade, a biblioteca pública legitima sua posição dentro da estrutura administrativa em que está inserida, se transformando num instrumento de interlocução entre o poder público e sociedade civil. Desse modo, esperamos que a história do SIC da BMA sirva de inspiração para outras instituições criarem seus próprios serviços de informação atendendo, assim, a contínua demanda por informação da sociedade.

\section{REFERÊNCIAS}

BARDIN, Laurence. Análise de Conteúdo. Lisboa: 70, 1977.

BAUMAN, Z. Vida líquida. Rio de Janeiro: Jorge Zahar, 2007. 
BIBLIOTECA MÁRIO DE ANDRADE (São Paulo, SP). Balcão de informações. São Paulo, [198?].

BIBLIOTECA MÁRIO DE ANDRADE (São Paulo, SP). Coordenação Técnica de Referência e Informação. Relatório anual. São Paulo, 2005.

BIBLIOTECA MÁRIO DE ANDRADE (São Paulo, SP). Seção de Referência e informação. Análise de obras de referência da Biblioteca Mário de Andrade. São Paulo, 1995

BIBLIOTECA MÁRIO DE ANDRADE (São Paulo, SP). Seção de Referência e Informação. Relatório anual. São Paulo, 1992.

BIBLIOTECA MÁRIO DE ANDRADE (São Paulo, SP). Seção de Referência e Informação. Relatório anual. São Paulo, 1993.

BIBLIOTECA MÁRIO DE ANDRADE (São Paulo, SP). Seção de Referência e Informação. Relatório anual. São Paulo, 1994.

BIBLIOTECA MÁRIO DE ANDRADE (São Paulo, SP). Seção de Referência e Informação. Relatório anual. São Paulo, 1995.

BIBLIOTECA MÁRIO DE ANDRADE (São Paulo, SP). Seção de Referência e Informação. Relatório anual. São Paulo, 1996.

BIBLIOTECA MÁRIO DE ANDRADE (São Paulo, SP). Seção de Referência e Informação. Relatório anual. São Paulo, 2002.

BIBLIOTECA MÁRIO DE ANDRADE (São Paulo, SP). Seção de Referência e Informação. Relatório anual. São Paulo, 2003.

BIBLIOTECA MÁRIO DE ANDRADE (São Paulo, SP). Seção de Referência e Informação. Relatório anual. São Paulo, 2007.

BIBLIOTECA MÁRIO DE ANDRADE (São Paulo, SP). Seção de Referência e Informação. Relatório anual. São Paulo, 2008.

BIBLIOTECA MÁRIO DE ANDRADE (São Paulo, SP). Seção de Referência e Informação. Relatório anual SIC. São Paulo, [1993].

BIBLIOTECA MÁRIO DE ANDRADE. História da Biblioteca Mário de Andrade. Disponível em: http://www.prefeitura.sp.gov.br/cidade/secretarias/cultura/bma/historico/index.php?p=7653 . Acesso em: 12 set. 2017.

NEGRÃO, M. B (Coord.) Projeto Sistema de Informação para o Cidadão. São Paulo: PMSP, 1989.

NEGRÃO, M. B.; SANTIAGO, M. Da G de O.; PÁSCOA, N. R. V. B. Biblioteca pública e informação: análise preliminar na Biblioteca Mário de Andrade. São Paulo : BMA, 1982. Atualização dos dados apresentado no I CLABD.

NEGRÃO, M. B.; SANTIAGO, M. Da G. De O.; PASCOA, N. R. V. B. Biblioteca pública e informação: análise preliminar na Biblioteca Mário de Andrade. In: CONGRESSO LATINO AMERICANO DE BIBLIOTECONOMIA E DOCUMENTAÇÃO, 1., Salvador, 1980. Anais... Salvador: CLBD, 1981. 
REDE NACIONAL DE PESQUISA. Popularização da internet: introdução ao uso de correio eletrônico e web. Rio de Janeiro, 1997.

RETRATOS da leitura no Brasil. 4. ed. [São Paulo, SP]: Instituto Pró-Livro, 2016. Disponível em: <http://prolivro.org.br/home/images/2016/Pesquisa_Retratos_da_Leitura_no_Brasil__2015.pdf>. Acesso em: 15 set. 2017.

SALGADO, D. M. Informatização dos acervos das bibliotecas do Sistema Municipal de Bibliotecas: histórico e adequações. São Paulo: CSMB, 2008.

TAKAHASHI, T. (Org.) Sociedade da Informação no Brasil: livro verde. Brasília: MCT, 2000.

VOGADO, I. M. Serviço de Informação ao Cidadão. São Paulo: BMA, [200?].

VILLANI, E. SIC da Mário de Andrade [mensagem pessoal]. Mensagem recebida por luanaseveriano@yahoo.com.br em 09 jan 2014.

\section{Agradecimentos}

A oportunidade de conhecer um pouco mais da Biblioteca Mário de Andrade foi incrível: registramos aqui nossa admiração pelos profissionais que lá atuaram e deixaram a sua marca na história da biblioteconomia brasileira. À toda equipe da BMA que nos ajudaram nesta pesquisa e, em especial, Elvira Villani, Juliana Marques e William Okubo, agradecemos pela hospitalidade, presteza e gentileza. 